\title{
Endoscopic nasal versus open approach for the management of sinonasal adenocarcinoma: A pooled-analysis of 1826 patients
}

\author{
Giuseppe Meccariello, MD, ${ }^{1 \star}$ Alberto Deganello, MD, PhD, ${ }^{1}$ Olivier Choussy, MD, ${ }^{2}$ Oreste Gallo, MD, ${ }^{1}$ Daniele Vitali, MD, ${ }^{1}$ Dominique De Raucourt, MD, ${ }^{3}$ \\ Christos Georgalas, MD, PhD, DLO, FRCS(ORL-HNS) ${ }^{4}$
}

\begin{abstract}
${ }^{1}$ Academic Clinic of Otolaryngology and Head and Neck surgery, Department of Surgery and Translational Medicine, University of Florence, Florence, Italy, ${ }^{2}$ ENT Department, Rouen University Hospital, Rouen, France, ${ }^{3}$ ENT Department, Comprehensive Cancer Centre, Caen, France, ${ }^{4}$ Endoscopic Skull Base Center, Department of Otorhinolaryngology, Academic Medical Center, University of Amsterdam, Amsterdam, The Netherlands.
\end{abstract}

Accepted 13 June 2015

Published online 3 September 2015 in Wiley Online Library (wileyonlinelibrary.com). DOl 10.1002/hed.24182

ABSTRACT: Background. Surgical resection represents the gold standard for the treatment of sinonasal malignancies. This study reviewed the published outcomes on endoscopic surgery or endoscopic-assisted surgery versus open approach for the management of sinonasal adenocarcinomas.

Methods. PubMed, EMBASE, the Cochrane Library, and CENTRAL electronic databases were searched for English language articles on endoscopic surgery, endoscopic-assisted surgery, and open approach for sinonasal adenocarcinomas. Each article was examined for patient data and outcomes for analysis.

Results. Thirty-nine articles including 1826 patients were used for the analysis. The endoscopic surgery and endoscopic-assisted surgery showed low rates of major complications $(6.6 \%$ and $25.9 \%$, respec- tively) compared to open approaches $(36.4 \% ; p<.01)$. The incidence of local failure was lower in the endoscopic surgery group as compared with open approach patients $(17.8 \%$ vs $38.5 \% ; p<.01$, respectively). The multivariate Cox regression model showed a worst overall survival related to advanced $T$ classification and open approach.

Conclusion. From the existing body of data, there is growing evidence that endoscopic nasal resection is a safe surgical option in the management of sinonasal adenocarcinomas. (c) 2015 Wiley Periodicals, Head Neck 38: E2267-E2274, 2016

KEY WORDS: adenocarcinoma, endoscopy, paranasal sinus, postoperative complications, patient outcome assessment

\section{INTRODUCTION}

Sinonasal malignancies pose a diagnostic and therapeutic challenge because of their location, resulting symptoms, and presentation mimicking benign lesions. ${ }^{1}$ The incidence of nasal and paranasal cancers in most relevant series is less than 1 per 100,000 per year. The ethmoid sinuses are mostly involved (between 5\% and 30\%), and adenocarcinoma is the most frequent malignancy of the ethmoid sinuses. ${ }^{2}$ Primary adenocarcinomas of the sinonasal tract are a diverse group of malignancies that can be initially classified as salivary (5\% to $10 \%$ ) and nonsalivary types. ${ }^{3}$ The World Health Organization classification of nonsalivary gland type sinonasal adenocarcinomas considers the categories: high-grade and low-grade adenocarcinomas of nonintestinal type and intestinal-type adenocarcinoma (ITAC) of colonic and mucinous subtypes. ${ }^{4}$ Because symptoms are usually similar to inflammatory sinusitis, the diagnosis may be delayed and tumors are

*Corresponding author: G. Meccariello, Academic Clinic of Otolaryngology and Head and Neck Surgery, University of Florence, Largo Brambilla 3, 50139 Firenze, Italy. E-mail: drmeccariello@gmail.com

This work was presented at the 25th European Rhinology Society Congress, Amsterdam, The Netherlands, June 26, 2014. diagnosed at advanced stages. As with other malignancies, the presence of unilateral symptoms, typically obstruction, rhinorrhea, and epistaxis, should serve as a warning sign for the clinician. Men are affected 2 to 6 times more often than women, reflecting occupational factors. In most series, the cohorts are relatively small and often no distinction is made among the several subtypes of adenocarcinomas. ${ }^{5}$ Surgical resection with negative margins, followed by adjuvant radiotherapy for advanced lesions, represents the gold standard for the management of sinonasal adenocarcinomas. Inability to control local disease is recognized as the cause of death in sinonasal malignancies, highlighting the importance of complete surgical resection at the primary site. ${ }^{6}$ In this light, numerous open surgical approaches were used to deal with the complex anatomy of the paranasal sinuses and adjacent structures. Although traditional surgical management is successful in yielding 5-year survival rates ranging from $40 \%$ to $70 \%$, open approaches carry specific complications, functional, and cosmetic risks, even with proper execution. ${ }^{7-9}$ Recently, endoscopic techniques gained popularity in the management of benign and malignant sinonasal tumors. However, endoscopic management of malignant neoplasms, such as sinonasal adenocarcinoma, is still under evaluation. ${ }^{5}$ Evidence-based guidelines on this topic are lacking because of the absence of randomized 


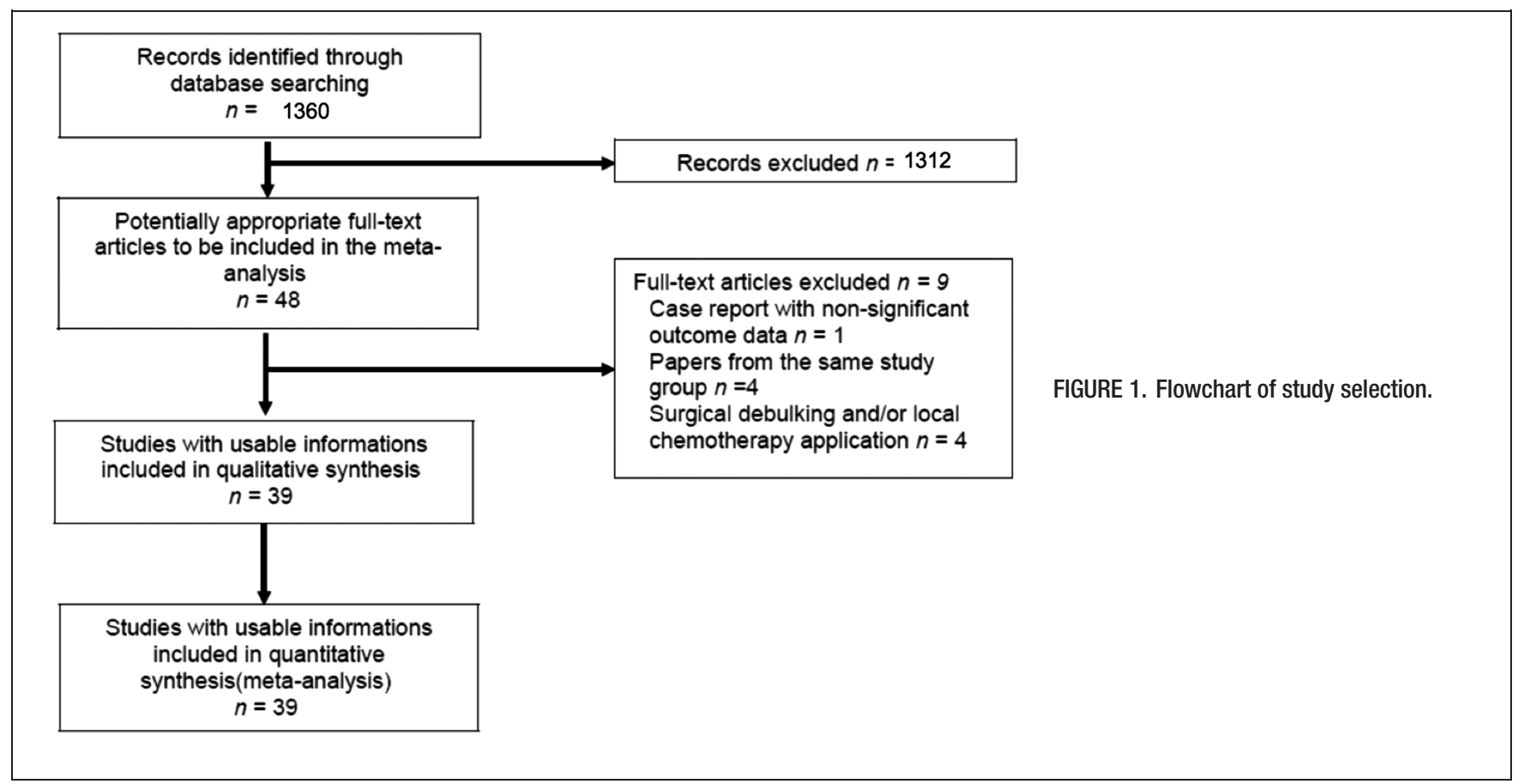

control trials, the low incidence of sinus adenocarcinoma that renders prospective studies difficult, and because of the widely variable reporting methods used with data from various histopathological types often aggregated together. Consequently, the purpose of this study was to compile and analyze outcome data in patients who received surgical treatment (endoscopic or open surgery) for sinonasal adenocarcinoma taking into account the variety of reporting methods for outcomes and tumor characteristics found across the literature on this entity.

\section{MATERIALS AND METHODS}

\section{Literature search protocol}

A comprehensive review of the English language literature on the surgical management of sinonasal adenocarcinomas was performed using PubMed, EMBASE, the Cochrane Library, and CENTRAL electronic databases (see Figure 1). Three searches using the keywords (1) surgery OR endoscopic OR craniofacial OR open approach, (2) adenocarcinoma OR malignancy OR tumor, and (3) paranasal OR sinonasal OR nasal were performed. These searches were combined with the AND function to find all relevant articles. The following inclusion criteria were applied to each article: (1) available information on outcome data with survival statistics related to the treatment of sinonasal or skull base adenocarcinomas, and (2) data concerning the type of surgical resection: endoscopic, or endoscopic assisted, or open approaches/craniofacial resection. ${ }^{7,9-46}$ When multiple articles were published by a single institution ${ }^{8,47-49}$ with updated follow-up on their patient populations, the most recent publication was used for analysis to maximize accuracy of follow-up data and reduce the risk of redundancy., ${ }^{9,41}$ Articles not meeting the inclusion criteria were excluded. Further exclusion criteria were: case reports without significant outcome data, ${ }^{50}$ reports on surgical debulking, and studies regarding local 5-fluorouracil applications. ${ }^{51-54}$ To further reduce the risk of an incomplete literature search, a manual search through the references of the included articles was performed.

\section{Analysis protocol}

Data from the studies were first extracted and assessed by the principal investigator (M.G.) and thereafter independently by 2 coauthors (D.A. and G.C.) using standardized data forms. Articles were examined for data resolution with the intent to perform a meta-analysis. Different methods of meta-analyses were considered in reviewing the literature to seek results that would provide meaningful analysis with the least risk of introducing biases. The quality assessment of diagnostic accuracy studies (QUADAS-2) tool was used to evaluate relevant study design characteristics of the included articles. ${ }^{55}$ A graphical display of QUADAS-2 results is shown in Figure 2. Based on the surgical treatment, 3 groups were defined: endoscopic surgery, endoscopic-assisted surgery, and open approach. The articles were analyzed to extrapolate all information for each treated patient about age, sex, occupational exposure, smoking, tumor staging, total admission time, adjuvant therapies, disease-free survival (in months), events of local recurrence, regional recurrence, distant metastasis, total follow-up time (in months), and survival. However, survival data were limited in the endoscopicassisted surgery group; thus, we compared only survival data from endoscopic surgery and open approach groups. The articles were also reviewed for data concerning the occurrence of perioperative and postoperative complications. A major complication was defined as at least one reported event of: cerebrospinal fluid leak, hemorrhage or severe epistaxis, stroke, severe pneumocephalus, meningitis, brain abscess, sepsis, or postoperative death. A minor complication was noted as at least one reported event of: light or moderate epistaxis, light or moderate pneumocephalus, agitation, minor subdural blood collection, central 


\section{Proportion of studies with low, high or unclear RISK OF BIAS}

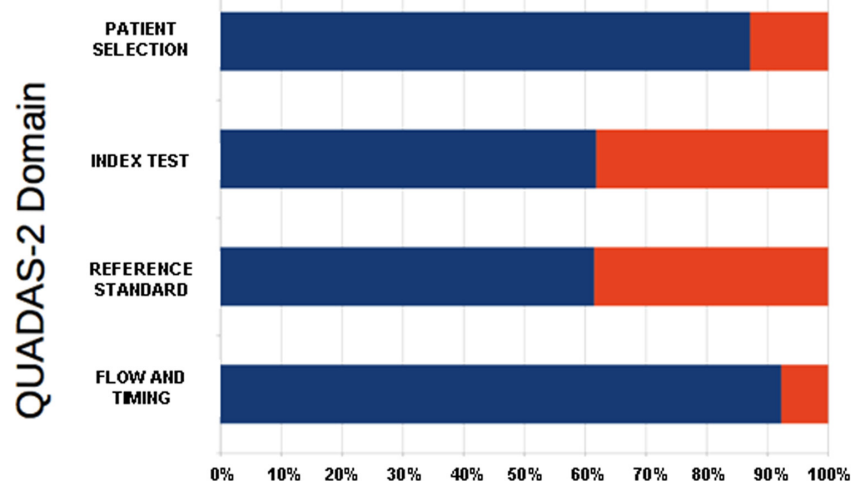

Proportion of studies with low, high or unclear CONCERNS regarding APPLICABILITY

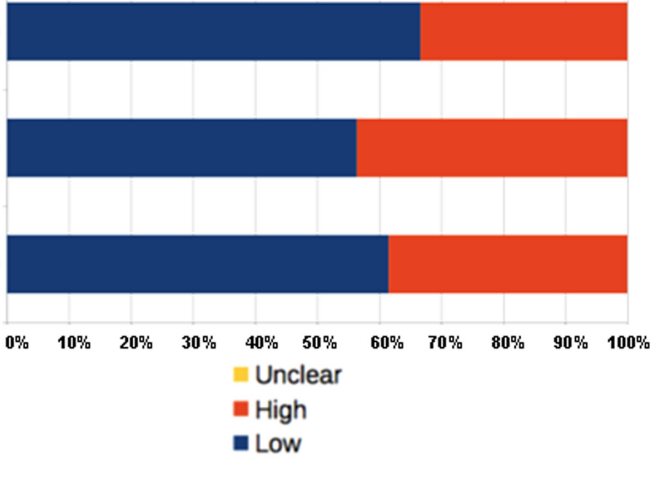

FIGURE 2. Graphical display for quality assessment of diagnostic accuracy studies (QUADAS)-2 results.

venous catheter infection, fever, deep venous thrombosis, epilepsy, headache, pneumonia, hallucinations, cranial nerve palsy, anisocoria, diplopia, or epiphora.

\section{Statistical analysis}

To test the differences among groups, the Fisher's exact test was used for categorical data, whereas the $t$ test was used for continuous data. The role of each possible prognostic factor (univariate analysis) and their independent effect (multivariate analysis) was explored using logistic regression model or Cox proportional hazard model, as appropriate. Unfortunately, because of discrepancies in the presentation of survival data, including follow-up, it was impossible to calculate Kaplan-Meier curves. Probability values lower than .05 were considered statistically significant. All analyses were performed with STATA 12.0 software (Stata, College Station, TX).

\section{RESULTS}

The search was performed in October 2014 and yielded 1360 articles, of which 39 articles met inclusion's criteria, ${ }^{7,9-46}$ comprising a total result of 1826 patients for ini-

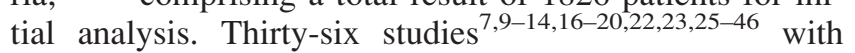
1404 cases included at least 3 years of follow-up and were included in the final analysis. All series were retrospective. Most series presented outcome data from heterogeneous histologies, $7,9,14-17,20-22,25-27,31,32,34,37-39,43$ at differing stages, of patients who received a variety of treatment strategies over a relatively long timeframe. The largest series of ethmoid adenocarcinomas was published by the French GETTEC group. ${ }^{30}$ Table 1 summarizes the extrapolated data from each included study. Palliative treatment was administered in 94 patients (5.1\%), 431 patients $(23.6 \%)$ received endoscopic surgery, 31 patients $(1.7 \%)$ received endoscopic-assisted surgery, and 1270 patients $(69.6 \%)$ underwent an open approach. Table 2 shows the patients' characteristics among surgical groups. In 2002 (with implementation starting from 2003), the American Joint Committee on Cancer and the International Union Against Cancer published staging protocols for epithelial tumors arising from sinonasal complex. Of 29 articles published after 2003, 11 studies specifically used the sixth or seventh edition of the TNM staging system. ${ }^{24,29-31,35-37,41,42,44-46}$ The remaining articles did not provide any information on the staging of treated adenocarcinomas except for 5 articles published before 2003, which used an earlier version of these guidelines. ${ }^{13,15-19}$ All but a few studies mentioned only the classification of the primary tumor (see Table 2), only 8 articles reported $\mathrm{N}$ classification at diagnosis, although these studies account for the larger series. ${ }^{17,19,27,30,35,36,44,46}$ In total, we had $\mathrm{T}$ classification information for 1221 patients. In $937 \mathrm{~N}$ classification cases, only $9 \mathrm{~N} 1(1 \%), 3 \mathrm{~N} 2 \mathrm{a}(0.3 \%), 3 \mathrm{~N} 2 \mathrm{~b}(0.3 \%)$, and $1 \mathrm{~N} 3$ $(0.1 \%)$ were recorded, the remaining 921 cases $(98.3 \%)$ were staged N0. Unfortunately, only 9 studies (364 patients) reported hospital discharge times. ${ }^{7,9,21,26,33,40,42,44,46}$ The available data showed a shorter hospitalization in the endoscopic surgery group ( $4.7 \pm 4.6$ days) compared to the endoscopic-assisted surgery and open approach groups $(9.2 \pm 3.7$ and $11.5 \pm 4.9$ days, respectively), which is statistically significant $(p<.01$; Figure 3$)$. Furthermore, 19 published articles recorded perioperative and postoperative complications comprising a total of 938 patients. ${ }^{13,15,21,23,24,26,27,29,31,33,36,39-46}$ The endoscopic surgery and endoscopic-assisted surgery showed low rates of major complications $(6.6 \%$ and $25.9 \%$, respectively) compared with open approaches $(36.4 \% ; p<.01)$. Postoperative deaths were recorded in 1 case of endoscopic-assisted surgery and in 7 cases of open approaches, no postoperative death was registered among patients who underwent endoscopic surgery $(p=.04)$. Minor complications occurred in $10 \%$ of the endoscopic surgery group and in $7.4 \%$ of the open approach group, whereas these were recorded in $33.3 \%$ of endoscopic-assisted surgery patients who underwent combined endoscopic and open approach (Figure 4). In 9 studies, adjuvant therapy was not documented or impossible to deduce. ${ }^{9,13,14,21,22,25,31,34,37}$ According to $\mathrm{T}$ classification, adjuvant radiotherapy (RT) was administered in $27.1 \%$ of T1 cases, $80 \%$ of T2 cases, $92.4 \%$ of T3 cases, $90.8 \%$ of T4a cases, and $91 \%$ of $\mathrm{T} 4 \mathrm{~b}$ cases. In the endoscopic surgery group, $78.9 \%$ of the cases received adjuvant RT, whereas the endoscopic-assisted surgery and open approach patients had adjuvant RT in $73.1 \%$ and $85.2 \%$, respectively $(p<.01)$. 


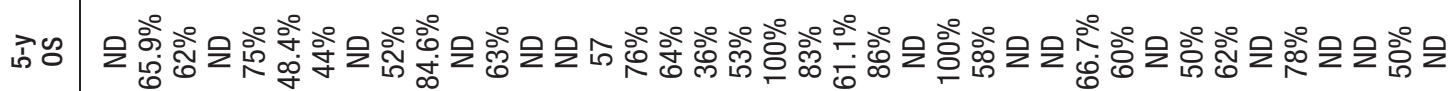

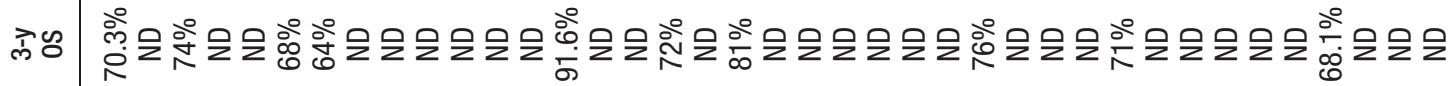

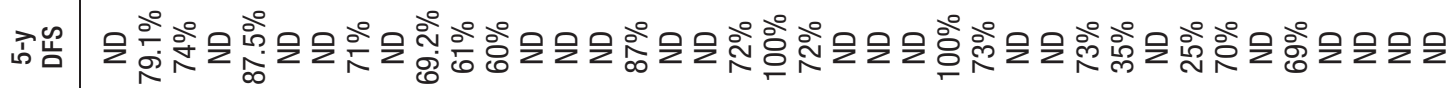

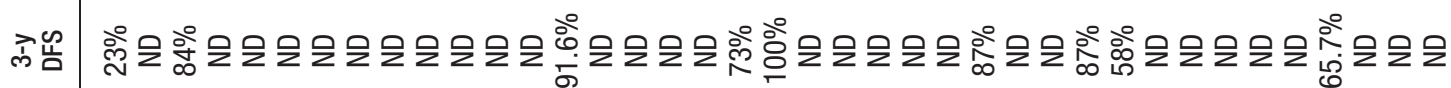

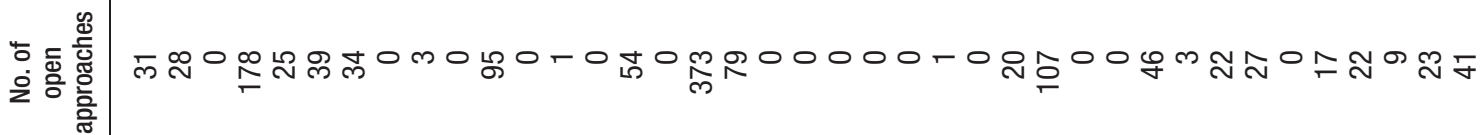

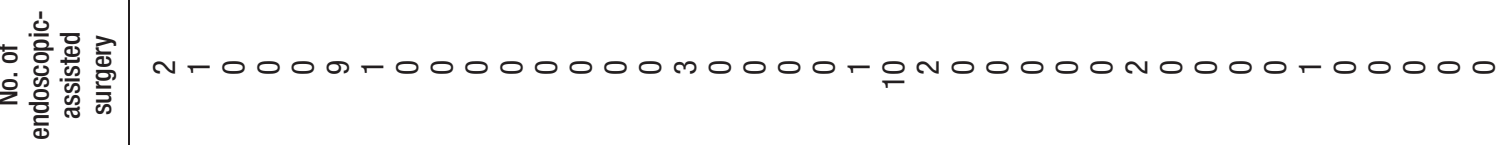

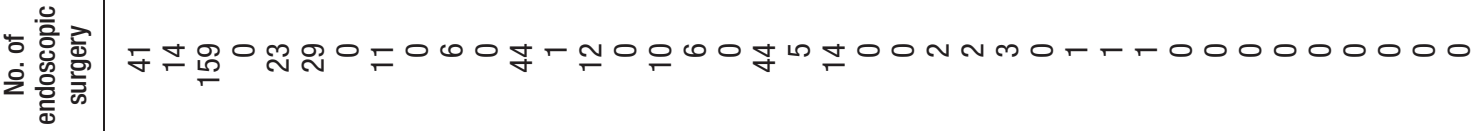

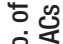

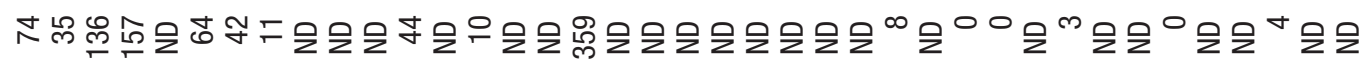

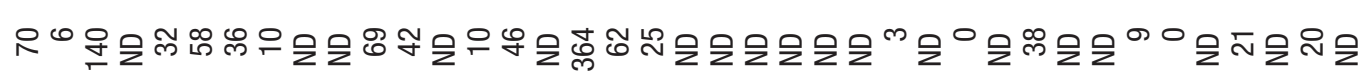

을

$\dot{s}$

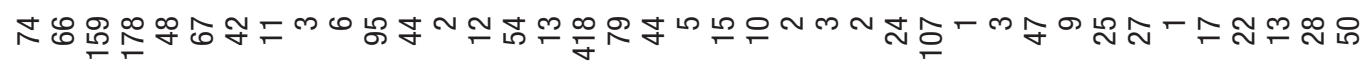

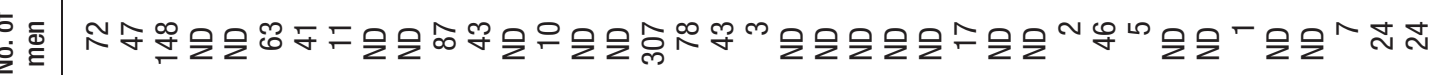

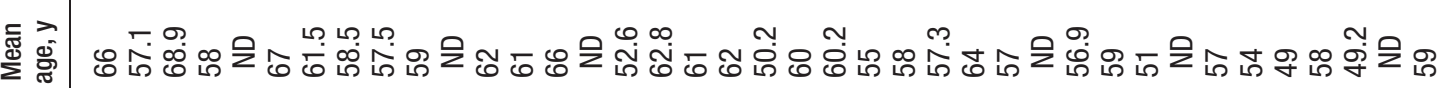

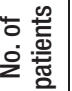

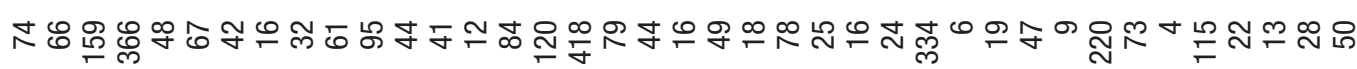

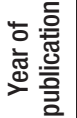

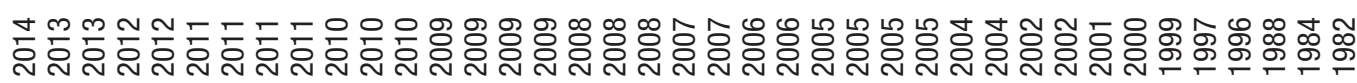

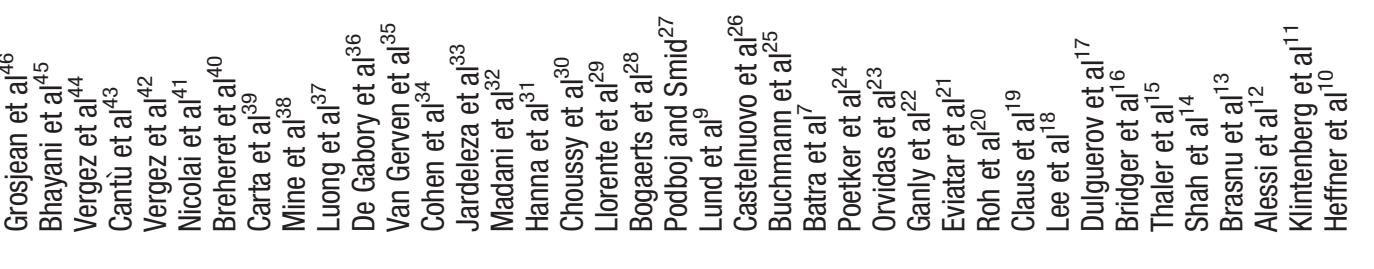


TABLE 2. Patients' characteristics among surgical groups

\begin{tabular}{|c|c|c|c|c|}
\hline Characteristics & Endoscopic surgery & Endoscopic-assisted surgery & Open approaches & $p$ value \\
\hline Male:female ratio & $360: 30$ & $20: 3$ & $543: 317$ & $<.01$ \\
\hline Age (mean \pm SD) & $64.3 \pm 13.3$ & $59.7 \pm 12.4$ & $61.1 \pm 12.8$ & $<.01$ \\
\hline ITAC:non-ITAC ratio & $242: 35$ & $11: 5$ & $612: 100$ & .11 \\
\hline No. of patients with wood dust exposure (\%) & $292(67.8)$ & $8(25.8)$ & $656(51.7)$ & $<.01$ \\
\hline No. of T1 (\%) & $52(12.8)$ & $1(3.7)$ & $56(7.1)$ & $<.01$ \\
\hline No. of T2 $(\%)$ & 169 (41.4) & $2(7.4)$ & $244(31)$ & \\
\hline No. of T3 (\%) & $83(20.3)$ & $4(14.8)$ & $178(22.7)$ & \\
\hline No. of T4a (\%) & $68(16.7)$ & $8(29.6)$ & $188(23.9)$ & \\
\hline No. of $T 4 b(\%)$ & $36(8.8)$ & $12(44.4)$ & $120(15.3)$ & \\
\hline No. of NO (\%) & $253(98.8)$ & $2(100)$ & 603 (98.4) & .25 \\
\hline No. of N1 (\%) & $3(1.2)$ & $0(0)$ & $4(0.7)$ & \\
\hline No. of N2a (\%) & $0(0)$ & $0(0)$ & $2(0.3)$ & \\
\hline No. of N2b (\%) & $0(0)$ & $0(0)$ & $3(0.5)$ & \\
\hline No. of N2c (\%) & $0(0)$ & $0(0)$ & $1(0.2)$ & \\
\hline
\end{tabular}

Abbreviation: ITAC, intestinal-type adenocarcinoma.

For what concerns the outcome and survival, statistics varied among the articles, and, in some studies, data were not amenable for meta-analysis. ${ }^{24,25,30-32,34}$ The mean follow-up time was 51.9 \pm 45.8 months (range, 1-360 months), with $46.4 \pm 37.6$ months (range, 2-180 months) in the endoscopic surgery group and 53.6 \pm 47.6 months (range, 1-360 months) in the open approach group $(p=.09)$. Within the available data, 536 failure events were reported: 424 local $(31.5 \%), 15$ regional $(1.1 \%)$, and 97 distant $(7.2 \%)$ failures, resulting in crude disease-free survival (DFS) of $60.7 \%$ and local recurrence free survival of $67.6 \%$. The crude DFS, locoregional relapse-free survival, and overall survival (OS) according to T classification between endoscopic surgery and open approach groups is shown in Table 3. Univariate and multivariate logistic regression analysis demonstrated that advanced $\mathrm{T}$ classification and open approach are statistically related to a high rate of major complications (odds ratio $[\mathrm{OR}]=6.1 ; p<.01$ and $\mathrm{OR}=3.5 ; p<.01$, respectively). Univariate and multivariate Cox regression model showed that advanced $\mathrm{T}$ classification and open approach are statistically related to the high rate of local relapses (see Table 4). Regarding the OS, the univariate Cox regression model highlighted the relationship among non-ITAC, advanced $\mathrm{T}$ classification, and bad prognosis, albeit the statistical significance persisted only for advanced $\mathrm{T}$ classification and open approach in a multivariate model (see Table 5).

\section{DISCUSSION}

Endoscopic surgery is increasingly and effectively used for sinonasal inflammatory diseases, even showing intracranial extension, and benign tumors ${ }^{56}$; nevertheless, for malignant tumors, this approach is in its relative infancy. A comprehensive analysis of the existing evidence would help to serve as a barometer for the state-of-the-art and to suggest future directions. Given that different types of tumors have several treatment survival implications for patients, we focused this analysis on the surgical management of sinonasal adenocarcinomas comparing outcomes between endoscopic surgery and traditional open approaches. The potential benefits of endoscopic resec- tions in sinonasal adenocarcinomas are numerous, including lack of facial incisions, excellent visualization and illumination of the surgical site, minimal trauma, shorter hospital stay, and lower costs. ${ }^{57}$ However, any treatment in sinonasal malignancies must be primarily judged by its efficacy. In that respect, our study is not conclusive. This is indeed a pooled analysis of patient data, rather than a comparative meta-analysis. This is inevitable, as, up to now, there are no comparative studies (and certainly no randomized controlled trials) comparing endoscopic with external approaches for adenocarcinomas.

The main problem in comparing different interventions is Simpson's paradox (ie, the effect of case mix); in our case, the proportion of patients with T1/T2 versus T3/T4 tumors in the endoscopic versus the open approaches, which could erroneously lead to false conclusions regarding their efficacy.

It is true that smaller tumors are more likely to be treated endoscopically, and this is indeed what we found within our data. However, comparing results by $\mathrm{T}$ classification, we found that endoscopic management was associated with better OS and DFS across almost all tumor classifications.

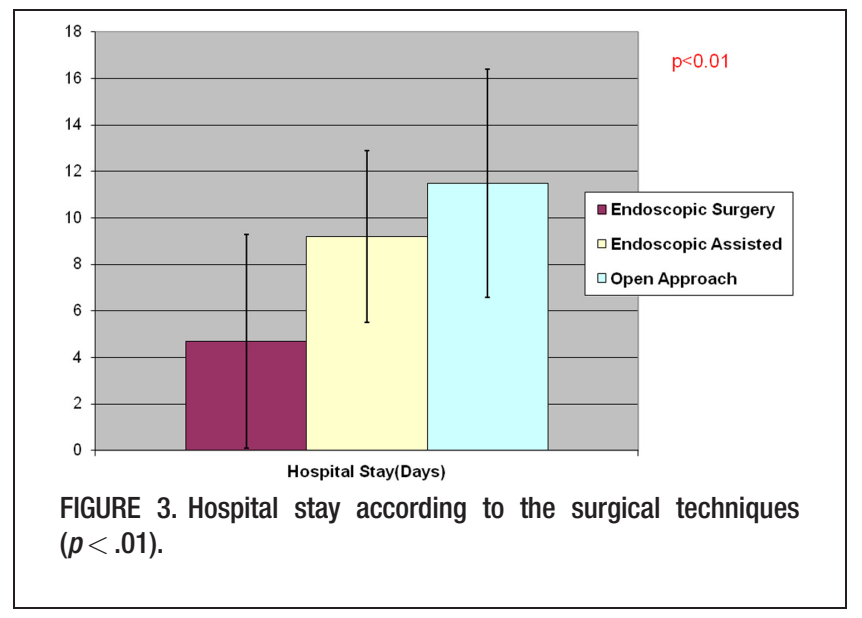




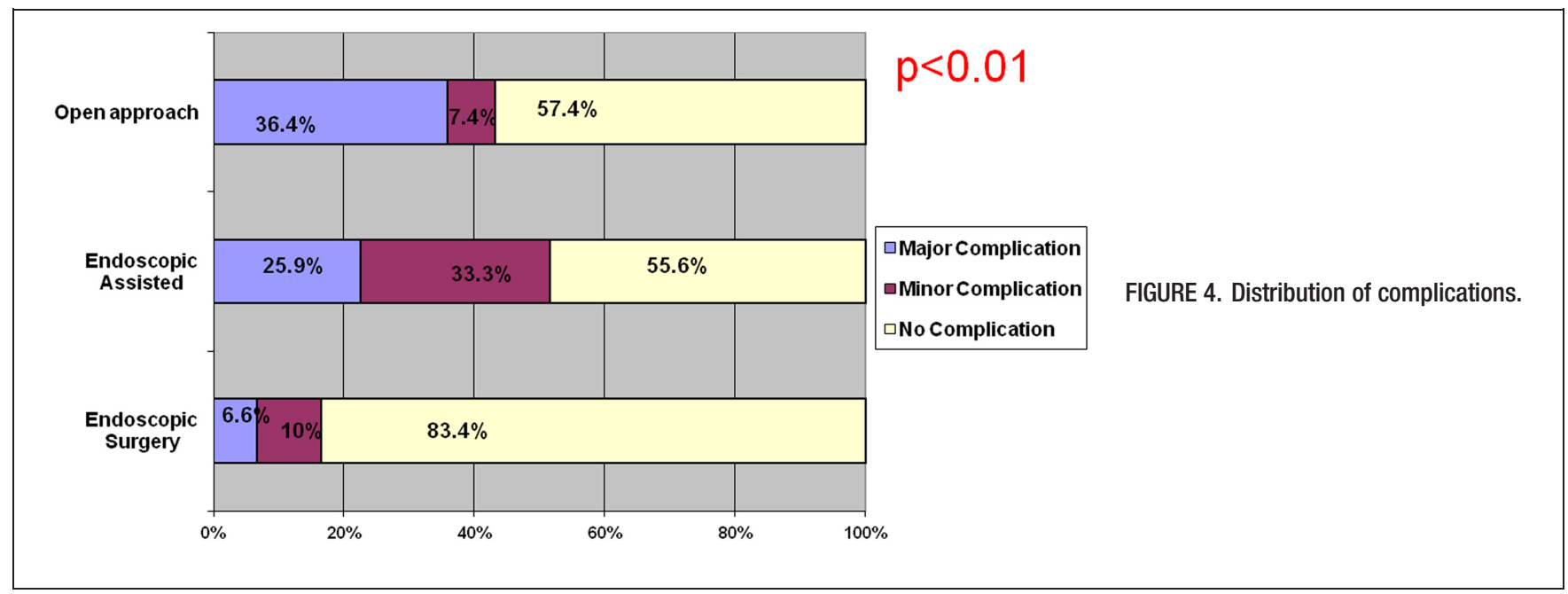

An issue is the possible reporting bias. It is true that the most experienced surgeons with the best results would be the first to publish their results. Unfortunately, this is true in all surgical series, and we can only acknowledge it.

In our analysis, we found a statistically lower rate of major and minor complications in endoscopic surgery (16.6\%) compared with open approaches $(43.8 \% ; p<.01)$. Postoperative deaths were recorded only within patients who underwent either endoscopic-assisted surgery or open approach. Of note, the open craniectomy might represent a risk factor in itself for the development of postoperative complications; in fact, the higher rate of complications in endoscopic-assisted surgery and open approach groups is mainly related to this external approach. Furthermore, the hospital stay in the endoscopic surgery group was statistically shorter compared with the endoscopic-assisted surgery and open approach groups $(p<.01)$. Almost all series largely used postoperative RT in the majority of the cases, and its use is reasonable in a district surrounded by noble structures where wide clear margins are often difficult to obtain $^{7,10-12,15-20,23,24,26-30,32,33,35,36,39-46}$; nevertheless, no randomized or even controlled trials of its precise role for sinonasal adenocarcinomas are available. This does not mean that RT plays no role in the management of sinonasal adenocarcinomas, but highlights the importance of a complete surgical resection. Outcomes are reported as combined results with and without RT. Patients treated with adjuvant RT are more likely to have locally advanced tumors and to be high-grade and/or to have positive margins, and are not comparable with those treated with surgery alone. Because of this understandable bias a conclusion cannot be drawn on its precise role. The overall local recurrence rate was reported as $32.5 \%$ with a rate of $17.8 \%$ for the endoscopic surgery group and $38.5 \%$ in the open approach group. Nevertheless, a recurrence can occur even 10 years or more after the initial treatment. The application of endoscopic techniques for the management of malignant sinonasal tumors is still controversial. The primary concern worries about the adherence to the oncologic principle of en bloc excision with adequate margins. However, many sinonasal tumors have a small area of tissue invasion despite filling the nasal cavity and paranasal sinuses; furthermore, tumor growth into sinuses and skull

TABLE 3. The crude survivals according to T classification

\begin{tabular}{|c|c|c|c|}
\hline T classifications & Endoscopic surgery group & Open approach group & $p$ value \\
\hline \multicolumn{4}{|l|}{$\mathrm{T} 1$} \\
\hline DFS (no. of survivals) & $81 \%(34)$ & $80 \%(28)$ & .57 \\
\hline Local recurrence-free survival (no. of survivals) & $81 \%(34)$ & $77.1 \%(27)$ & .45 \\
\hline OS (no. of survivals) & $81.3 \%(39)$ & $76.4 \%(42)$ & .36 \\
\hline \multicolumn{4}{|l|}{$\mathrm{T} 2$} \\
\hline DFS (no. of survivals) & $83.2 \%(134)$ & $64.4 \%(139)$ & $<.01$ \\
\hline Local recurrence-free survival (no. of survivals) & $84.5 \%(136)$ & $66.7 \%(144)$ & $<.01$ \\
\hline OS (no. of survivals) & $84.2 \%(139)$ & $71.4 \%(162)$ & $<.01$ \\
\hline \multicolumn{4}{|l|}{ T3 } \\
\hline DFS (no. of survivals) & $80.8 \%(63)$ & $61 \%(94)$ & $<.01$ \\
\hline Local recurrence-free survival (no. of survivals) & $85.9 \%(67)$ & $66.7 \%(102)$ & $<.01$ \\
\hline OS (no. of survivals) & $79.5 \%(62)$ & $66.5 \%(111)$ & .03 \\
\hline \multicolumn{4}{|l|}{ T4 } \\
\hline DFS (no. of survivals) & $70 \%(86)$ & $41 \%(187)$ & $<.01$ \\
\hline Local recurrence-free survival (no. of survivals) & $77.2 \%(95)$ & $57 \%(305)$ & $<.01$ \\
\hline OS (no. of survivals) & $66.4 \%(81)$ & $47.1 \%(254)$ & $<.01$ \\
\hline
\end{tabular}

Abbreviations: DFS, disease-free survival; OS, overall survival. 
TABLE 4. Univariate and multivariate Cox regression model for local relapses

\begin{tabular}{|c|c|c|c|c|c|c|}
\hline & \multicolumn{3}{|c|}{ Univariate } & \multicolumn{3}{|c|}{ Multivariate } \\
\hline & HR & $p$ value & $95 \% \mathrm{Cl}$ & HR & $p$ value & $95 \% \mathrm{Cl}$ \\
\hline ITAC & 0.82 & .24 & $0.59-1.14$ & 0.89 & .53 & $0.63-1.27$ \\
\hline T3-T4 classification & 1.8 & $<.01$ & $1.44-2.26$ & 1.69 & $<.01$ & $1.29-2.21$ \\
\hline Open approach & 1.88 & $<.01$ & $1.44-2.46$ & 2.57 & $<.01$ & $1.78-3.69$ \\
\hline
\end{tabular}

Abbreviations: HR, hazard ratio; 95\% Cl, confidence interval; ITAC, intestinal-type adenocarcinoma.

TABLE 5. Univariate and multivariate Cox regression model for overall survival

\begin{tabular}{|c|c|c|c|c|c|c|}
\hline & \multicolumn{3}{|c|}{ Univariate } & \multicolumn{3}{|c|}{ Multivariate } \\
\hline & HR & $p$ value & $95 \% \mathrm{Cl}$ & HR & $p$ value & $95 \% \mathrm{Cl}$ \\
\hline non-ITAC & 1.46 & $<.01$ & $0.53-1.88$ & 1.13 & .42 & $0.84-1.52$ \\
\hline T3-T4 classification & 2.3 & $<.01$ & $1.87-2.84$ & 2.1 & $<.01$ & $1.59-2.66$ \\
\hline Endoscopic surgery & 0.89 & .32 & $0.71-1.12$ & 0.62 & $<.01$ & $0.47-0.83$ \\
\hline
\end{tabular}

Abbreviations: HR, hazard ratio; 95\% Cl, confidence interval; non-ITAC, nonintestinal-type adenocarcinoma.

base regions often occurs by compression of bony structures rather than by direct invasion. En bloc excision of the entire tumor is not necessary; instead, en bloc resection of the area of invasion is performed with frozen section control confirming clear margins. In order to gain access to the area of invasion, it is frequently necessary to debulk the tumor first. Albeit this clearly violates the tumor, it does not violate normal tissue planes surrounding the malignant proliferation because the tumor is residing in an air-filled cavity, and furthermore there is no evidence that this intraoperative debulking increases the risk of local recurrence. In fact, there are multiple examples of other neoplasms that are removed in a piece-meal fashion without jeopardizing the results: inverted papillomas, and laser resection of laryngeal and pharyngeal carcinomas. Even with an open surgical approach (craniofacial resection), en bloc resection is not always possible because of the fragility and fragmentation of the specimen and the proximity to vital structures. Thus, it is the final resection margin that is crucial, and not the method of tumor removal. ${ }^{58}$ Nevertheless, there is no consensus regarding the indication and contraindication for endoscopic surgery as treatment for sinonasal adenocarcinomas. Some authors identified orbital involvement as a contraindication, ${ }^{28,48}$ whereas others argued that endoscopic surgery would still be an acceptable method. $^{27}$ Dural and intracranial extension, however, served as a nearly universal contraindication to endoscopic surgery, ${ }^{15,25,26}$ but this dogma has also been challenged with the constant evolution of techniques, technology, and surgeons expertise. ${ }^{44,46,59}$ Histopathologic typing is strictly related to outcome with the poorly differentiated subtypes faring worse. Thus, survival is better in papillary and colonic (ITAC) type than in solid or mucinous type adenocarcinomas. ${ }^{60}$ Wood dust exposure as an etiologic factor that confers a better prognosis in the larger, but not all, series. $^{30,35,36}$ As ITAC is a subtype of adenocarcinoma showing histological features reminiscent of colonic adenomas and adenocarcinomas, new therapeutic approaches, such as targeted therapy with monoclonal antibodies against epidermal growth factor receptor might, in the future, be helpful in the therapeutic approach of these lesions. ${ }^{61}$

The variability encountered in the reported data was detailed in this study. This variability is partially indicative of the rare nature of this tumor and the changes in staging with time. Another aspect is the difficulty in the interpretation of the oncologic results reported in some studies, given that different histologies with different patterns of behavior and prognosis where mixed. Furthermore, the staging information was not available in all series, thus, this potential bias might distort the results of this study. Nevertheless, for advanced $\mathrm{T}$ classifications, surprisingly, the endoscopic surgery showed better outcomes in survival than the traditional open approach.

\section{CONCLUSION}

Based on the available published data, endoscopic management of sinonasal adenocarcinomas seems to be a safe and effective treatment modality. Recommendations for future studies include the implementation of prospective multi-institutional studies with detailed data regarding histology, staging, surgical treatment, adjuvant treatment, minor/major complications, and oncologic results.

\section{Acknowledgments}

The authors thank the GETTEC group for providing their data, and Giuseppe Meccariello wishes to express words of gratitude to all coworkers for their support and drafting of this manuscript.

\section{REFERENCES}

1. Waldron J, Witterick I. Paranasal sinus cancer: caveats and controversies. World J Surg 2003;27:849-855.

2. Robin PE, Powell DJ, Stansbie JM. Carcinoma of the nasal cavity and paranasal sinuses: incidence and presentation of different histological types. Clin Otolaryngol Allied Sci 1979;4:431-456.

3. Franchi A, Santucci M, Wenig B. Adenocarcinomas. Barnes L, Evenson JW, Reichart P, Sidransky D, editors. In: World Health Organization classification of tumours. Pathology and genetics of head and neck tumours. Lyon, France: IARC; 2005. pp 20-23.

4. Kleinsasser O, Schroeder HG. Adenocarcinomas of the inner nose after exposure to wood dust. Morphological findings and relationships between 
histopathology and clinical behavior in 79 cases. Arch Otorhinolaryngol 1988;245:1-15.

5. Lund VJ, Chisholm EJ, Takes RP, et al. Evidence for treatment strategies in sinonasal adenocarcinoma. Head Neck 2012;34:1168-1178.

6. Alvarez I, Suárez C, Rodrigo JP, Nuñez F, Caminero MJ. Prognostic factors in paranasal sinus cancer. Am J Otolaryngol 1995;16:109-114.

7. Batra PS, Citardi MJ, Worley S, Lee J, Lanza DC. Resection of anterior skull base tumors: comparison of combined traditional and endoscopic techniques. Am J Rhinol 2005;19:521-528.

8. Howard DJ, Lund VJ, Wei WI. Craniofacial resection for tumors of the nasal cavity and paranasal sinuses: a 25-year experience. Head Neck 2006; 28:867-873.

9. Lund V, Howard DJ, Wei WI. Endoscopic resection of malignant tumors of the nose and sinuses. Am J Rhinol 2007;21:89-94.

10. Heffner DK, Hyams VJ, Hauck KW, Lingeman C. Low-grade adenocarcinoma of the nasal cavity and paranasal sinuses. Cancer 1982;50:312-322.

11. Klintenberg C, Olofsson J, Hellquist H, Sökjer H. Adenocarcinoma of the ethmoid sinuses. A review of 28 cases with special reference to wood dust exposure. Cancer 1984;54:482-488.

12. Alessi DM, Trapp TK, Fu YS, Calcaterra TC. Nonsalivary sinonasal adenocarcinoma. Arch Otolaryngol Head Neck Surg 1988;114:996-999.

13. Brasnu D, Laccourreye O, Bassot V, Laccourreye L, Naudo P, Roux FX. Cisplatin-based neoadjuvant chemotherapy and combined resection for ethmoid sinus adenocarcinoma reaching and/or invading the skull base. Arch Otolaryngol Head Neck Surg 1996;122:765-768.

14. Shah JP, Kraus DH, Bilsky MH, Gutin PH, Harrison LH, Strong EW. Craniofacial resection for malignant tumors involving the anterior skull base. Arch Otolaryngol Head Neck Surg 1997;123:1312-1317.

15. Thaler ER, Kotapka M, Lanza DC, Kennedy DW. Endoscopically assisted anterior cranial skull base resection of sinonasal tumors. Am J Rhinol 1999; 13:303-310.

16. Bridger GP, Kwok B, Baldwin M, Williams JR, Smee RI. Craniofacial resection for paranasal sinus cancers. Head Neck 2000;22:772-780.

17. Dulguerov P, Jacobsen MS, Allal AS, Lehmann W, Calcaterra T. Nasal and paranasal sinus carcinoma: are we making progress. A series of 220 patients and a systematic review. Cancer 2001;92:3012-3029.

18. Lee CF, Liu TC, Hsu CJ, Chen YS. Sinonasal adenocarcinoma: clinical study of nine cases in Taiwan. Acta Otolaryngol 2002;122:887-891.

19. Claus F, Boterberg T, Ost P, et al. Postoperative radiotherapy for adenocarcinoma of the ethmoid sinuses: treatment results for 47 patients. Int $J$ Radiat Oncol Biol Phys 2002;54:1089-1094.

20. Roh HJ, Batra PS, Citardi MJ, Lee J, Bolger WE, Lanza DC. Endoscopic resection of sinonasal malignancies: a preliminary report. Am J Rhinol 2004;18:239-246.

21. Eviatar E, Vaiman M, Shlamkovitch N, Segal S, Kessler A, Katzenell U. Removal of sinonasal tumors by the endonasal endoscopic approach. Isr Med Assoc J 2004;6:346-349.

22. Ganly I, Patel SG, Singh B, et al. Craniofacial resection for malignant paranasal sinus tumors: report of an International Collaborative Study. Head Neck 2005;27:575-584.

23. Orvidas LJ, Lewis JE, Weaver AL, Bagniewski SM, Olsen KD. Adenocarcinoma of the nose and paranasal sinuses: a retrospective study of diagnosis, histologic characteristics, and outcomes in 24 patients. Head Neck 2005;27:370-375.

24. Poetker DM, Toohil RJ, Loehrl TA, Smith TL. Endoscopic management of sinonasal tumors: a preliminary report. Am J Rhinol 2005;19:307-315.

25. Buchmann L, Larsen C, Pollack A, Tawfik O, Sykes K, Hoover LA. Endoscopic techniques in resection of anterior skull base/paranasal sinus malignancies. Laryngoscope 2006;116:1749-1754

26. Castelnuovo P, Belli E, Bignami M, Battaglia P, Sberze F, Tomei G. Endoscopic nasal and anterior craniotomy resection for malignant nasoethmoid tumors involving the anterior skull base. Skull Base 2006;16:15-18.

27. Podboj J, Smid L. Endoscopic surgery with curative intent for malignant tumors of the nose and paranasal sinuses. Eur J Surg Oncol 2007;33:10811086.

28. Bogaerts S, Vander Poorten V, Nuyts S, Van den Bogaert W, Jorissen M. Results of endoscopic resection followed by radiotherapy for primarily diagnosed adenocarcinomas of the paranasal sinuses. Head Neck 2008;30: $728-736$.

29. Llorente JL, Nunez F, Rodrigo JP, et al. Sinonasal adenocarcinomas: our experience [in Spanish]. Acta Otorrinolaringol Esp 2008;59:235-238.

30. Choussy O, Ferron C, Védrine PO, et al. Adenocarcinoma of ethmoid: a GETTEC retrospective multicenter study of 418 cases. Laryngoscope 2008:118:437-443.

31. Hanna E, DeMonte F, Ibrahim S, Roberts D, Levine N, Kupferman M. Endoscopic resection of sinonasal cancers with and without craniotomy: oncologic results. Arch Otolaryngol Head Neck Surg 2009;135:1219-1224.

32. Madani I, Bonte K, Vakaet L, Boterberg T, De Neve W. Intensity-modulated radiotherapy for sinonasal tumors: Ghent University Hospital update. Int J Radiat Oncol Biol Phys 2009;73:424-432.

33. Jardeleza C, Seiberling K, Floreani S, Wormald PJ. Surgical outcomes of endoscopic management of adenocarcinoma of the sinonasal cavity. Rhinology 2009; $47: 354-361$.
34. Cohen MA, Liang J, Cohen IJ, Grady MS, O’Malley BW Jr, Newman JG. Endoscopic resection of advanced anterior skull base lesions: oncologically safe? ORL J Otorhinolaryngol Relat Spec 2009;71:123-128.

35. Van Gerven L, Jorissen M, Nuyts S, Hermans R, Vander Poorten V. Longterm follow-up of 44 patients with adenocarcinoma of the nasal cavity and sinuses primarily treated with endoscopic resection followed by radiotherapy. Head Neck 2011;33:898-904.

36. de Gabory L, Maunoury A, Maurice-Tison S, et al. Long-term singlecenter results of management of ethmoid adenocarcinoma: 95 patients over 28 years. Ann Surg Oncol 2010;17:1127-1134.

37. Luong A, Citardi MJ, Batra PS. Management of sinonasal malignant neoplasms: defining the role of endoscopy. Am J Rhinol Allergy 2010;24:150-155.

38. Mine S, Saeki N, Horiguchi K, Hanazawa T, Okamoto Y. Craniofacial resection for sinonasal malignant tumors: statistical analysis of surgical outcome over 17 years at a single institution. Skull Base 2011;21:243-248.

39. Carta F, Kania R, Sauvaget E, Bresson D, George B, Herman P. Endoscopy skull-base resection for ethmoid adenocarcinoma and olfactory neuroblastoma. Rhinology 2011;49:74-79.

40. Breheret R, Laccourreye L, Jeufroy C, Bizon A. Adenocarcinoma of the ethmoid sinus: retrospective study of 42 cases. Eur Ann Otorhinolaryngol Head Neck Dis 2011;128:211-217.

41. Nicolai P, Villaret AB, Bottazzoli M, Rossi E, Valsecchi MG. Ethmoid adenocarcinoma--from craniofacial to endoscopic resections: a singleinstitution experience over 25 years. Otolaryngol Head Neck Surg 2011; 145:330-337.

42. Vergez S, Martin-Dupont N, Lepage B, De Bonnecaze G, Decotte A, Serrano E. Endoscopic vs transfacial resection of sinonasal adenocarcinomas. Otolaryngol Head Neck Surg 2012;146:848-853.

43. Cantu G, Solero CL, Miceli R, et al. Anterior craniofacial resection for malignant paranasal tumors: a monoinstitutional experience of 366 cases. Head Neck 2012;34:78-87.

44. Vergez S, du Mayne MD, Coste A, et al. Multicenter study to assess endoscopic resection of 159 sinonasal adenocarcinomas. Ann Surg Oncol 2014; 21:1384-1390.

45. Bhayani MK, Yilmaz T, Sweeney A, et al. Sinonasal adenocarcinoma: a 16-year experience at a single institution. Head Neck 2014;36:1490-1496.

46. Grosjean R, Gallet P, Baumann C, Jankowski R. Transfacial versus endoscopic approach in the treatment of woodworker's nasal adenocarcinomas. Head Neck 2015;37:347-356.

47. Villaret AB, Yakirevitch A, Bizzoni A, et al. Endoscopic transnasal craniectomy in the management of selected sinonasal malignancies. Am J Rhinol Allergy 2010;24:60-65.

48. Nicolai P, Castelnuovo P, Lombardi D, et al. Role of endoscopic surgery in the management of selected malignant epithelial neoplasms of the nasoethmoidal complex. Head Neck 2007;29:1075-1082.

49. Goffart Y, Jorissen M, Daele J, et al. Minimally invasive endoscopic management of malignant sinonasal tumours. Acta Otorhinolaryngol Belg 2000;54:221-232.

50. Shah UK, Hybels RL, Dugan J. Endoscopic management of low-grade papillary adenocarcinoma of the ethmoid sinus: case report and review the literature. Am J Otolaryngol 1999;20:190-194.

51. Hatano A, Aoki K, Iino T, Seino Y, Kato T, Moriyama H. Endoscopic endonasal surgery in the management of selected malignant nasoethmoidal tumors. Auris Nasus Larynx 2010;37:334-339.

52. Wadhera R, Gulati SP, Garg A, Ghai A, Kumar S. Primary adenocarcinoma of the frontal sinus. Ear Nose Throat J 2011;90:E23-E25.

53. Knegt PP, Ah-See KW, vd Velden LA, Kerrebijn J. Adenocarcinoma of the ethmoidal sinus complex: surgical debulking and topical fluorouracil may be the optimal treatment. Arch Otolaryngol Head Neck Surg 2001;127:141-146.

54. Almeyda R, Capper J. Is surgical debridement and topical 5 fluorouracil the optimum treatment for woodworkers' adenocarcinoma of the ethmoid sinuses. A case-controlled study of a 20 -year experience. Clin Otolaryngol 2008;33:435-441.

55. Whiting PF, Rutjes AW, Westwood ME, et al. QUADAS-2: a revised tool for the quality assessment of diagnostic accuracy studies. Ann Intern Med 2011;155:529-536.

56. Meccariello G, Deganello A, Mannelli G, et al. Allergic fungal rhinosinusitis infiltrating anterior skull base and clivus. Auris Nasus Larynx 2013;40: 405-408.

57. Devaiah AK, Lee MK. Endoscopic skull base/sinonasal adenocarcinoma surgery: what evidence exists? Am J Rhinol Allergy 2010;24:156-160.

58. Snyderman CH, Carrau RL, Kassam AB, et al. Endoscopic skull base surgery: principles of endonasal oncological surgery. J Surg Oncol 2008;97: 658-664.

59. de Bruin R, van Furth WR, Verbaan D, Georgalas C, Fokkens WF, Reinartz SM. Initial experiences with endoscopic rhino-neurosurgery in Amsterdam. Eur Arch Otorhinolaryngol 2014;271:1525-1532.

60. Franchi A, Gallo O, Santucci M. Clinical relevance of the histological classification of sinonasal intestinal-type adenocarcinomas. Hum Pathol 1999; 30:1140-1145.

61. Franchi A, Fondi C, Paglierani M, Pepi M, Gallo O, Santucci M. Epidermal growth factor receptor expression and gene copy number in sinonasal intestinal type adenocarcinoma. Oral Oncol 2009;45:835-838. 